\title{
INFLUENCE OF ADDITIVE ADSORPTION ON PROPERTIES OF PULSE DEPOSITED COFeNi ALLOYS.
}

\author{
Stanko R. Brankovic ${ }^{*}$, , Natasa Vasiljevic*, Timothy J. Klemmer \\ and Earl C. Johns* \\ Seagate Research Center \\ 1251 Waterfront Place, Pittsburgh PA 15222
}

\begin{abstract}
In this paper we present results obtained for pulse current deposition of the CoFeNi magnetic alloys. Depending on the magnitude of pulse currents used in electrodeposition experiments, different conditions for additive adsorption are formed influencing the surface quality, the crystal structure and the coercivity of the CoFeNi films. The potential of the electrode surface during the pulse stage relative to the potential of the maximum additive adsorption is investigated and correlated to the $\mathrm{CoFeNi}$ alloy composition and concentration of incorporated $\mathrm{C}, \mathrm{S}$, and $\mathrm{O}$ inclusions in the deposit. The content of $\mathrm{S}, \mathrm{O}$, and $\mathrm{C}$ in the CoFeNi alloy is found to be dependent on the potential of the electrode surface during the pulse stage and the potential of the maximum additive incorporation is determined. The anomalous co-deposition effect was found to be moderate in the potential range where maximum surface coverage of additives is expected causing the composition of the CoFeNi films and their crystal structure to have relatively mild change for a broad range of pulse current densities.
\end{abstract}

\footnotetext{
*Electrochemical Society active member.

z e-mail: Stanko.R.Brankovic@seagate.com
} 
Key words: pulse deposition, additives, adsorption, inclusions, double layer. 


\section{INTRODUCTION}

Organic additives have been commonly used in the electrodeposition of magnetic alloys for many years ${ }^{1}$. The properties of magnetic alloys are found to be critically dependent on the choice of one or more additives used in electrodeposition process. Besides a commonly seen action of leveling and brightening of the deposit, the benefit of additives in plating bath was usually attributed to improvement in the grain size and the crystal structure of the deposit ${ }^{2,3}$, stress reduction ${ }^{4}$, suppression of hydrogen evolution ${ }^{4}$, and improved corrosion resistance of the deposit ${ }^{5}$. Recently, it was demonstrated that the appropriate choice of the additives and bath chemistry could substantially improve the magnetic properties of the CoFeNi films ${ }^{2,6,7,8,9}$. Magnetically very soft CoFeNi alloys with coercivity less than 2 Oe and high magnetic moment $(>1.8 \mathrm{~T})$ were produced leading to substantial breakthrough in electrodeposited magnetic head core materials used for high density magnetic recording ${ }^{2,7,9}$.

Depending on the particular additive used and the conditions at the electrochemical interface during the electrodeposition process, different atomic interstitials like S, C, O, N and B or their intermetalic compounds are found in the magnetic films. Their amount can be as high as several atomic percents (at $\%)$ or barely detectible with conventional analytical techniques. Since the presence of small amounts of foreign atoms in the crystal lattice of magnetic alloys ${ }^{10}$ are sometimes crucial or detrimental for desired magnetic properties and crystal structure ${ }^{3,5}$, it is very important to understand the correlation between the parameters defining the additive adsorption on metal surface and the rate of their incorporation into the deposit.

In this paper we present results obtained for pulse current deposition (PCD) of CoFeNi alloys, investigating the potential of maximum additive adsorption on the CoFeNi surface, the electrode potential during pulse deposition and their mutual correlation and effect on the deposit's properties, structure and concentration of additive related inclusions. The potential of maximum additive adsorption is determined by examining the double layer capacitance curves obtained from the impedance measurements. The amount of $\mathrm{S}, \mathrm{O}$, and $\mathrm{C}$ incorporated in the CoFeNi deposit for different pulse currents is correlated to the potential of the electrode surface during the pulse stage, and the approximate potential of the maximum additive incorporation is determined. Depending on the magnitude of the pulse current, different conditions for additive adsorption exist on the electrode surface, influencing the surface quality, crystal structure and coercivity of the CoFeNi films.

\section{EXPERIMENTAL}

The bath chemistry and additive content in the electrodeposition experiments have been well described previously on several occassions ${ }^{6,7,11}$. The background solution was a modified Watt's electrolyte containing $\mathrm{H}_{3} \mathrm{BO}_{3}$ and $\mathrm{NH}_{4} \mathrm{Cl}$ as buffers, and the $\mathrm{pH}$ of the solution was adjusted with diluted $\mathrm{HCl}$. Metal ions in the solution were obtained by dissolution of proper amounts of $\mathrm{CoCl}_{2} * 6 \mathrm{H}_{2} \mathrm{O}, \mathrm{FeCl}_{2} * 6 \mathrm{H}_{2} \mathrm{O}$ and $\mathrm{NiCl}_{2} * 6 \mathrm{H}_{2} \mathrm{O}$. The additives used in the deposition experiments were Sodium Lauryl Sulfate (SLS) and 
Saccharin $(0.1 \mathrm{~g} / \mathrm{L}$ SLS and $0.4 \mathrm{~g} / \mathrm{L}$ of Sach.). The CoFeNi films were deposited on $\mathrm{Cu}$ thin films with preferential $\{111\}$ texture. The approximate thickness of the CoFeNi films was $\sim 1 \pm 0.05$ microns ${ }^{12}$ and they were deposited using a standard paddle cell configuration $^{13}$ with 600 Oe magnetic field. The pulse current deposition experiments were performed under constant current control using in-house built power supply. The pulse current range was between $5 \mathrm{mAcm}^{-2}$ and $40 \mathrm{mAcm}^{-2}$ and all potentials in the text are quoted vs. standard $\mathrm{Ag}^{+} / \mathrm{AgCl} / \mathrm{Cl}^{-}$electrode. The electrochemical measurements and electrochemical impedance spectroscopy (EIS) measurements were performed on the electrodeposited $\mathrm{CoFeNi}$ films ${ }^{14}$ as the working electrode and in the background solution of $0.4 \mathrm{M} \mathrm{H}_{3} \mathrm{BO}_{3}+0.3 \mathrm{M} \mathrm{NH}{ }_{4} \mathrm{Cl}$. The $\mathrm{pH}$ of solution was adjusted to 2.8. The range of investigated frequencies was from $30 \mathrm{kHz}-1 \mathrm{~Hz}$, with the potential steps of $0.03 \mathrm{~V}$ and $0.05 \mathrm{~V}$ using a computer controlled EG\&G potentiostat/galvanostat model $263 \mathrm{~A}$ with EG\&G lock-in amplifier model 5210.

The X-ray Diffraction (XRD) measurements were performed on Philips X'pert PRO MRD system with automated stage and X-ray beam capabilities. Magnetic properties of the electrodeposited CoNiFe films were characterized using a BH Looper, model 109 from SHB instruments. The composition of the CoFeNi alloys is measured by Energy Dispersive X-ray spectroscopy (EDX) using Hitachi S-4500 scanning electron microscope with EDX detector from Oxford Instruments. Secondary Ion Mass Spectroscopy (SIMS) analysis of S, C, and O content in the CoFeNi films was done at Evans Analytical East on their in-house system ${ }^{15}$.

\section{RESULTS AND DISCUSSION}

\section{$\underline{\text { 3.1 Potential Transients Measurements }}$}

The pulse function used for the CoFeNi alloy deposition had a simple "on/off" profile (Figure 1).

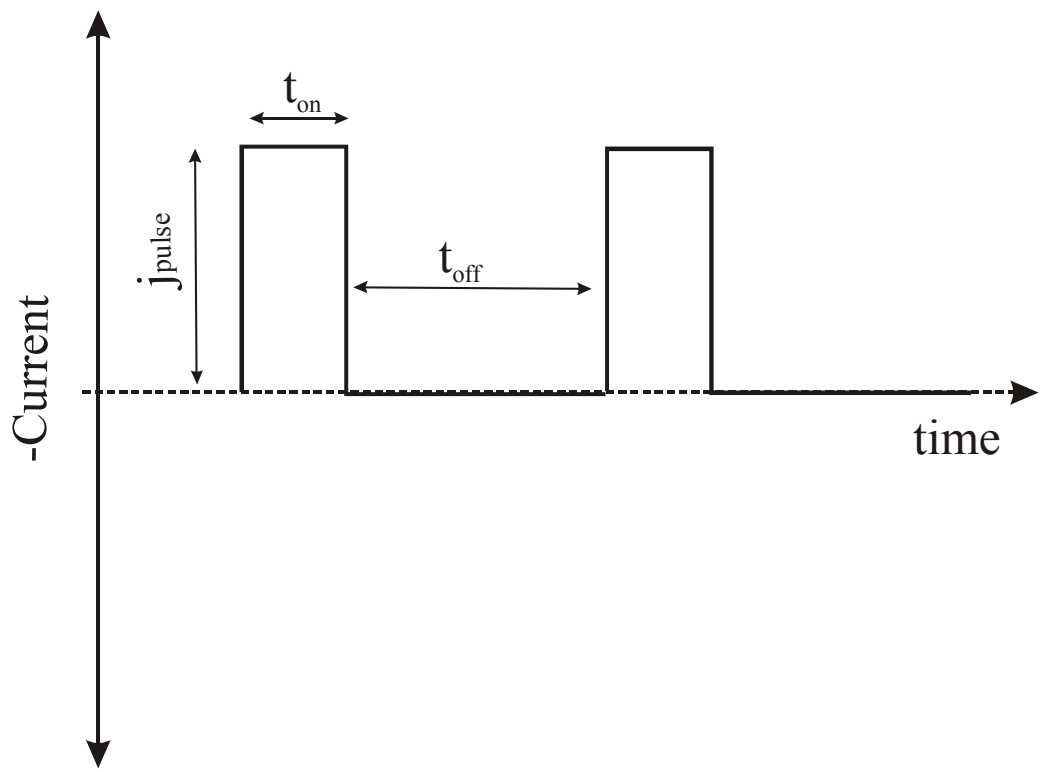

Figure 1. Pulse function used for deposition of the CoFeNi films. The $t_{\text {on }} / t_{\text {off }}=10 \%$. 


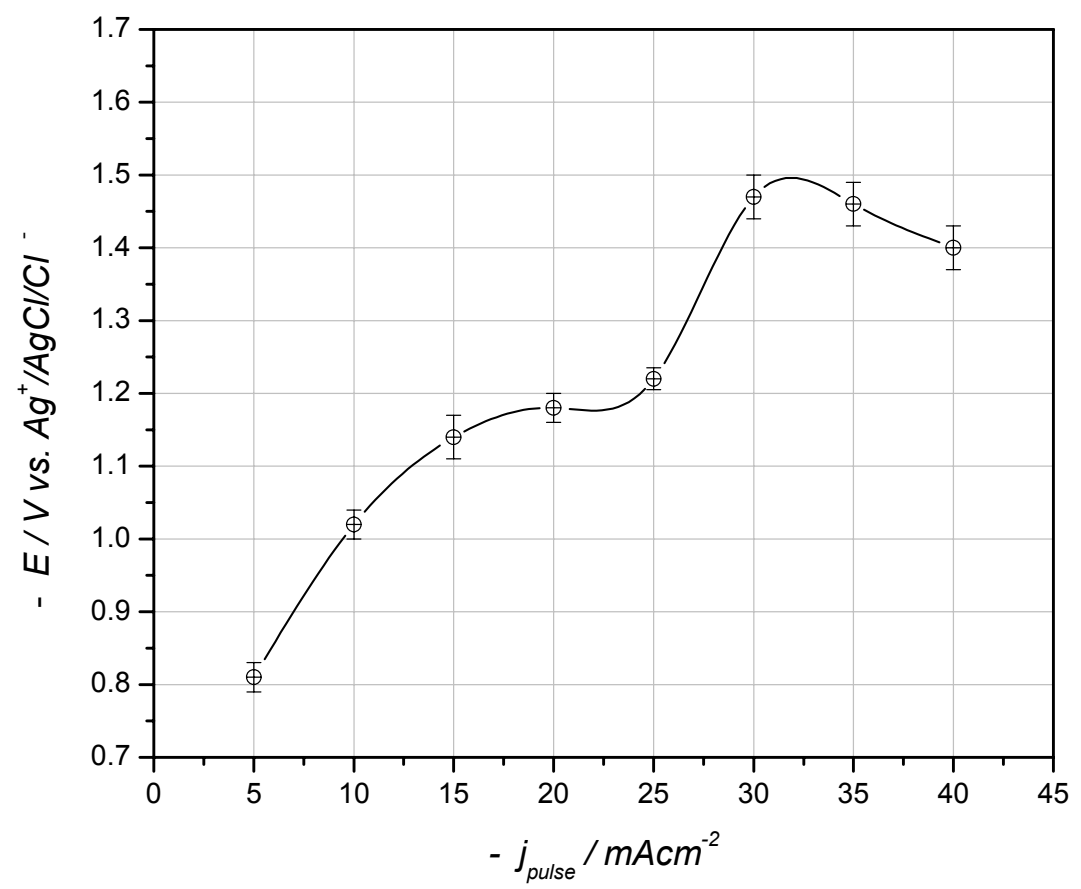

Figure 2. Potential of the CoFeNi surface during the pulse stage as a function of the magnitude of the pulse current density.

The potential transients during the pulse stage as a function of the different current densities used are presented in Figure 2. The potential of the electrode surface during the pulse stage shows an overall increase in the negative direction from -0.81 to $1.47 \mathrm{~V}$ as the pulse current density goes from $-5 \mathrm{mAcm}^{-2}$ to $-30 \mathrm{mAcm}^{-2}$. The increase of the potential of the electrode surface is not a monotone function of current density, but rather a dependence with three separate regions; $-5 \mathrm{mAcm}^{-2}$ to $-15 \mathrm{mAcm}^{-2}$ a steep increase, $-15 \mathrm{mAcm}^{-2}$ to $-25 \mathrm{mAcm}^{-2}$ a very mild increase and then from $-25 \mathrm{mAcm}^{-2}$ to $-30 \mathrm{mAcm}^{-2}$ a steep increase again. For current densities larger than $-30 \mathrm{mAcm}^{-2} \mathrm{a}$ significant $\mathrm{H}_{2}$ evolution was visible through the formation and release of $\mathrm{H}_{2}$ bubbles from the electrode surface. In this region the potential behavior is characterized with a gradual decrease toward more positive values from $-1.47 \mathrm{~V}$ to $-1.41 \mathrm{~V}$ (Figure 2).

\subsection{Electrochemical Impedance and Double Layer Measurements}

The electrochemical impedance spectra are collected within the same potential range that was observed during the potential transients measurements (Figure 2). The spectra are recorded for three different concentrations of additives; $1 \mathrm{~g} / \mathrm{L}(0.1 \mathrm{~g} / \mathrm{L} \mathrm{SLS}$ $+0.9 \mathrm{~g} / \mathrm{L}$ Saccharin), 0.5g/L (0.1 g/L SLS $+0.4 \mathrm{~g} / \mathrm{L}$ Saccharin) and $0.4 \mathrm{~g} / \mathrm{L}(0.1 \mathrm{~g} / \mathrm{L} \mathrm{SLS}+$ $0.3 \mathrm{~g} / \mathrm{L}$ Saccharin) having potential steps of $0.05 \mathrm{~V}, 0.03 \mathrm{~V}$ and $0.05 \mathrm{~V}$ respectively. The representative impedance spectra presented as Nyquist ${ }^{16}$ plots, for solution having $0.5 \mathrm{~g} / \mathrm{L}$ of additives, are shown in Figure 3. 


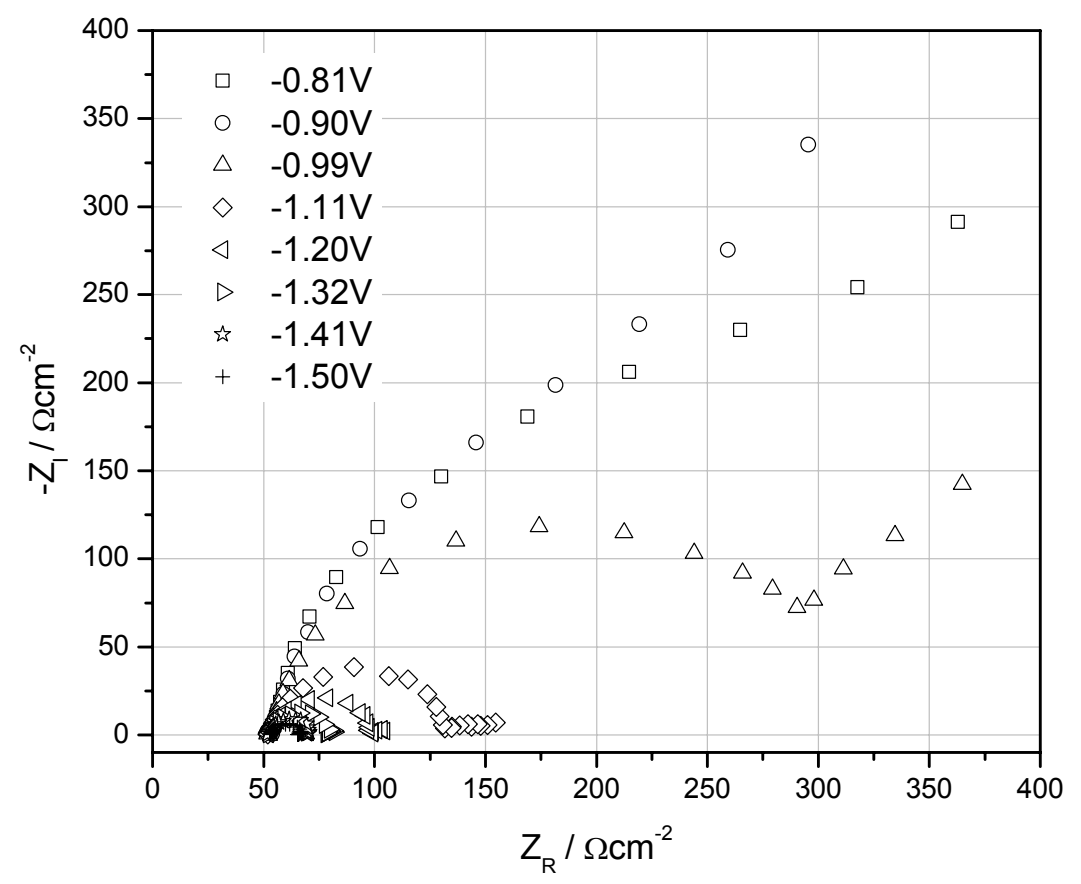

Figure 3. Electrochemical Impedance Spectroscopy for the CoFeNi electrode in solution containing $0.5 \mathrm{~g} / \mathrm{L}$ of additives $\left(0.4 \mathrm{~g} / \mathrm{L}\right.$ Saccharin and $0.1 \mathrm{~g} / \mathrm{L}$ of SLS) and $0.4 \mathrm{M} \mathrm{H}_{3} \mathrm{BO}_{3}$ $+0.3 \mathrm{M} \mathrm{NH}_{4} \mathrm{Cl}$ at $\mathrm{pH}=2.8$. Some spectra at different potentials are omitted for clarity purposes.

The impedance spectra for solutions containing $1 \mathrm{~g} / \mathrm{L}$ and $0.4 \mathrm{~g} / \mathrm{L}$ of additives are not shown but they have a very similar appearance to the ones presented here. Most of the spectra are showing clearly defined semicircles. In some cases, like for the spectra recorded at $-0.990 \mathrm{~V}$ and $-1.11 \mathrm{~V}$, the onset of the second semicircle is present indicating two distinctive processes occurring at the electrochemical interface. The spectra recorded in the potential range between $-0.8 \mathrm{~V}$ and $-0.9 \mathrm{~V}$ show a

strong presence of the diffusion influencing the shape of the EIS. All impedance spectra are fitted with the standard analog model describing the electrochemical interfaces with the presence of specific adsorption ${ }^{17}$ shown in Figure 4 . The details of the analog model are described in the figure captions. Before the final fit was accepted, bad data points from each frequency scan were extracted upon the examination of the plot of residuals and Kramers-Kronig ${ }^{18}$ extrapolation. The model provided very good fits for all solutions and every potential examined with an average $\chi^{2}$ values between $10^{-3}$ and $10^{-5}$. 


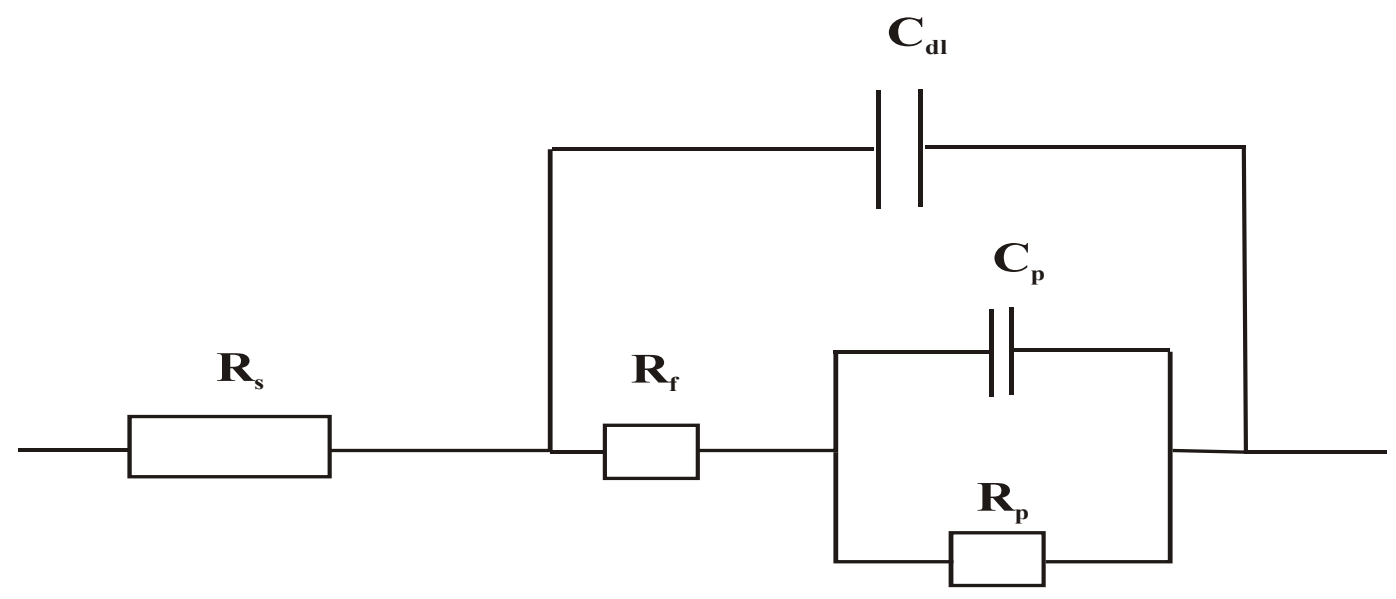

Figure 4. Analog circuit model used for fitting the impedance data. $R_{s}$ - ohmic resistance of the solution, $C_{d l}$-double layer capacitance, $R_{f}$-Faradic resistance (charge transfer resistance of hydrogen deposition reaction at investigated potentials), $C_{p}-$ pseudo capacitance (related to the specific adsorption of $\mathrm{Cl}^{-}, S L S$, Saccharin and other species on the electrode surface), $R_{p}$-charge transfer resistance corresponding to the discharge of specifically adsorbed species.

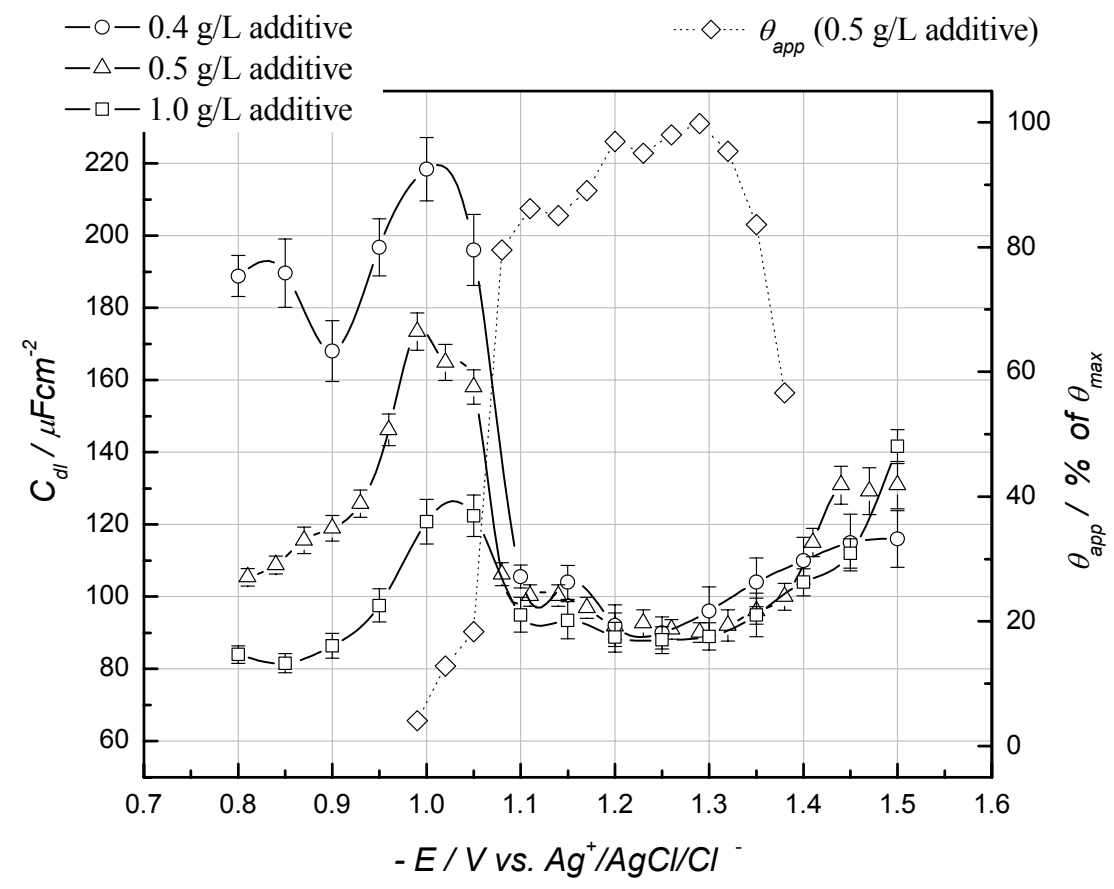

Figure 5. Double layer capacitance vs. potential dependence for the CoFeNi surface in solutions containing $0.4 \mathrm{~g} / \mathrm{L}$ (circles), $0.5 \mathrm{~g} / \mathrm{L}$ (triangles) and $1 \mathrm{~g} / \mathrm{L}$ (squares) of additives. Data obtained by fitting the model from Figure 4 to experimental data (Figure 3). Right axis represents the apparent coverage of additives on the CoFeNi surface in solution with $0.5 \mathrm{~g} / \mathrm{L}$ of additive ${ }^{26}$. The data are represented with diamonds and doted line. 
The results for double layer capacitance obtained from the fit of the model to the experimental data are presented in Figure 5. The double layer capacitance curve $\left(C_{d l}\right)$ shows a pronounced wide minimum (well) for all three additive concentrations. The literature data for the double layer minimum (potential of zero charge, $\mathrm{PZC}$ ) for $\mathrm{Fe}, \mathrm{Ni}$ and Co surfaces in different electrolytes ${ }^{19}$ as well as our measurements for PZC of CoFeNi surface in 10x diluted background solution at $\mathrm{pH} 2.8$ (data not shown here, PZC $=-1.15 \mathrm{~V}$ ) indicate that PZC is shifted towards more positive potentials from what we see as the minimum of double layer capacitance curves in the presence of additives ( -1.25 to $1.32 \mathrm{~V}$, Figure 5). This observation is consistent with the model of the double layer describing water dipole adsorption as energetically dependent on the charge (positive or negative) on the electrode surface ${ }^{20,21}$.

For $0.4 \mathrm{~g} / \mathrm{L}$ additive concentration the approximate potential range of the double layer well is between $-1.1 \mathrm{~V}$ and $-1.3 \mathrm{~V}$ (circles), for $0.5 \mathrm{~g} / \mathrm{L}$, between $-1.1 \mathrm{~V}$ and -1.39 $\mathrm{V}$ (triangles) and for $1 \mathrm{~g} / \mathrm{L}$, between $-1.1 \mathrm{~V}$ and $-1.45 \mathrm{~V}$. The broadening of the potential range for double layer minimum as well as no obvious dependence of the absolute minimum of $C_{d l}\left(\sim 90 \mu \mathrm{Fcm}^{-2}\right)$ on saccharin concentration in the bulk solution (Figure 5) are indications that the very strong adsorption of saccharin takes place or/and a certain type of the stable condensed film of mainly Saccharin forms on the surface of CoFeNi alloy $^{22}$. These results are in agreement with data reported for Saccharin adsorption on other metal surfaces ${ }^{3,23}$ and it is a significant for the formulation of the optimum Saccharin content in the baths used for electrodeposition of magnetic films ${ }^{11,24}$ as well as for better understanding of the leveling mechanism of this additive ${ }^{25,26}$.

In the sense of the double layer capacitance data from Figure 5, we can now reexamine the results presented in Figure 2. For Fe-like surfaces the $\mathrm{H}_{2}$ evolution current density has a significant contribution as a parasitic reaction during metal deposition at potentials more negative than $-0.622 \mathrm{~V}^{27}$. The mild increase in the potential of the CoNiFe surface from $-1.14 \mathrm{~V}$ to $-1.22 \mathrm{~V}$ during the pulse stage for current densities between $-15 \mathrm{mAcm}^{-2}$ and $-25 \mathrm{mAcm}^{-2}$ could be explained as a consequence of strong adsorption of Saccharin in this region (Figure 5). As known already, the Saccharin is having an inhibiting effect on $\mathrm{H}_{2}$ evolution ${ }^{4}$ when used as an additive. Due to this fact, the polarization of the electrode surface related to $\mathrm{H}_{2}$ evolution contributes less to the overall potential of the $\mathrm{CoFeNi}$ surface in the intermediate range of pulse current densities. This reflects on the correspondingly lower increase in the potential during the pulse stage for the same pulse current density increment as compared to the rest of the data in Figure 2. This observation has been indirectly re-confirmed by measuring higher current efficiency in the $-15 \mathrm{mAcm}^{-2}$ to $-25 \mathrm{mAcm}^{-2}$ pulse current range than for the other segments in Figure $2^{28}$.

\subsection{EDX Analysis of CoFeNi Alloys}

The composition of the CoFeNi alloys as a function of the pulse current density is presented in Figure 6. It is apparent a very gradual increase in Fe content (circles) from approximately $9 \pm 1$ at $\%$ to $15 \pm 1$ at $\%$ and a decrease in Ni content (triangles) from $12.5 \pm$ $1 \mathrm{at} \%$ to $7.3 \pm 1 \mathrm{at} \%$ as the current density increases from $-5 \mathrm{mAcm}^{-2}$ to $-40 \mathrm{mAcm}^{-2}$. The Co content (squares) is not changing with respect to the pulse current density to the extent larger than the error bar of the measurements so it can be considered constant, $\sim 78$ $\pm 1 \mathrm{at} \%$. The overall impression is that the data for $\mathrm{Ni}$ and Fe content vs. pulse current 
density can be also considered through the existence of the segments similar to the ones noted in Figure 2. The first segment is for the current densities between $-5 \mathrm{mAcm}^{-2}$ and $15 \mathrm{mAcm}^{-2}$. The increase (decrease) of $\mathrm{Fe}(\mathrm{Ni})$ content in this segment is steeper than for current densities between $-15 \mathrm{mAcm}^{-2}$ and $-25 \mathrm{mAcm}^{-2}$ where the composition stays almost constant. For the current densities lager than $-25 \mathrm{mAcm}^{-2}$ the trend of increase (decrease) of $\mathrm{Fe}(\mathrm{Ni})$ content is similar to what is observed in the first segment of $\mathrm{Fe}$ and Ni curves.

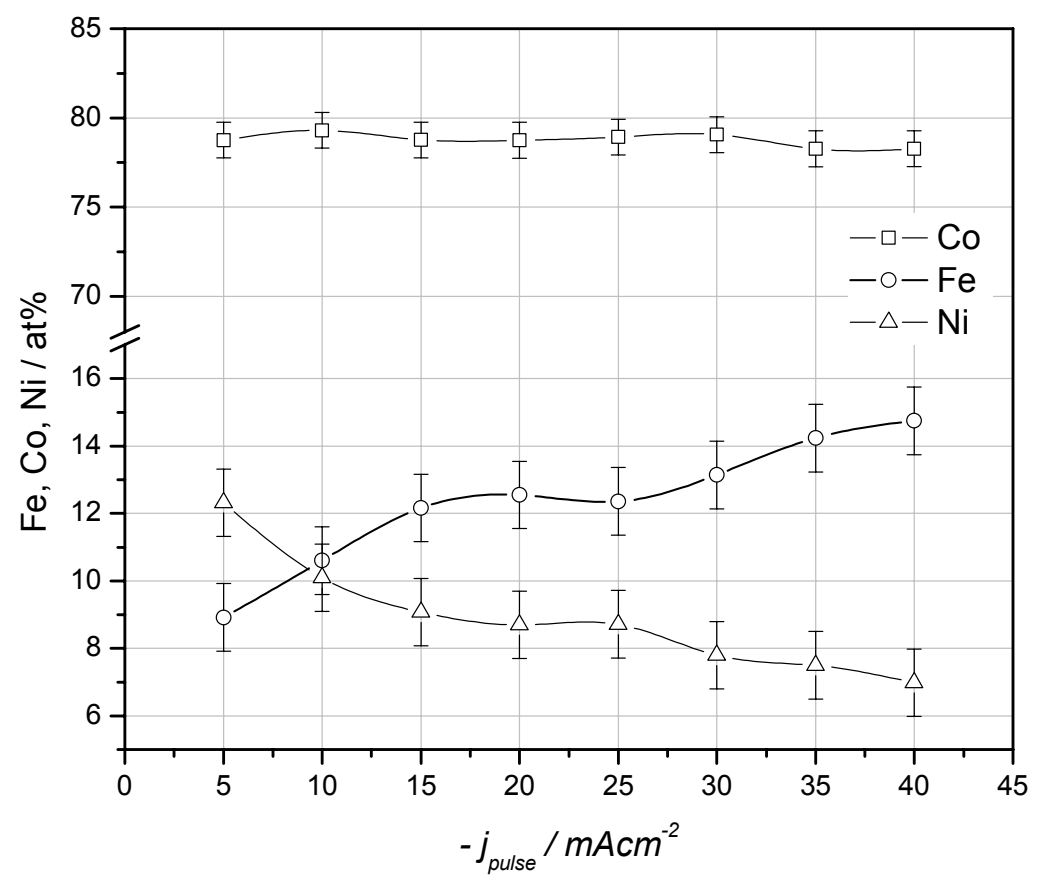

Figure 6. The CoFeNi alloy composition as a function of the pulse current density. Co (squares), $\mathrm{Fe}$ (circles), $\mathrm{Ni}$ (triangles).

On previous occasion, we described the method for design of the pulse function (Figure 1) which prevents the formation of the transport limitations or depletion of the metal ions at the electrochemical interface ${ }^{11}$. In these experiments, the same method was used to calculate the pulse function and the observed trend in compositional change of the CoFeNi deposit vs. pulse current density is unlikely to be associated to any diffusion limitation effects during the pulse stage. The observed trend of the overall increasing $\mathrm{Fe}$ content in the CoFeNi alloy with the higher pulse currents is in agreement with the predictions of the anomalous codeposition mode ${ }^{4,29}$. An increase in pulse current density results in a larger depletion rate of $\mathrm{H}^{+}$ions in the vicinity of the metal/solution interface. As a consequence, the formation of an insoluble $\mathrm{Fe}_{\mathrm{x}}(\mathrm{OH})_{\mathrm{y}}$ intermediate species adsorbed at the electrode surface occurs ${ }^{30}$, hindering the $\mathrm{Ni}$, and promoting the $\mathrm{Fe}$ deposition rate. A similar observation was reported previously for pulse reverse deposition of $\mathrm{CoFeNi}$ alloys $^{31}$. However the described effect is the weakest for the pulse current densities at which the electrode potential is in the rage of the maximum additive adsorption/coverage at CoFeNi surface $\left(\mathrm{j}=-15 \mathrm{mAcm}^{-2}\right.$ to $-25 \mathrm{mAcm}^{-2}$, Figure 5$)$. The adsorbed Saccharin in this potential regime, as mentioned previously, hinders the hydrogen evolution reaction ${ }^{4}$ 
causing the anomalous codeposition effect to be moderate and the composition of the $\mathrm{CoFeNi}$ alloy to be almost constant for a broad range of pulse current densities.

\subsection{Magnetic Properties}

Comparing the overall composition data with the expected magnitude of saturation magnetic flux density $\left(\mathrm{B}_{\mathrm{s}}\right)$ for the equilibrium ternary CoFeNi system ${ }^{32}$, it is expected that $\mathrm{B}_{\mathrm{s}}$ for all examined $\mathrm{CoFeNi}$ films is in the range $\sim 1.8 \mathrm{~T}$. The actual measurements of $B_{s}$ are confirming this fact. These data are presented in Figure 7. However, the coercivity of CoFeNi alloys measured for the easy magnetic axes is showing a decreasing trend from 1.4 Oe to 0.48 Oe as the pulse current density is increasing. Since the coercivity is a material property that is very important for high frequency dynamic switching during the recording process of magnetic heads, the reduction of $\sim 1$ Oe with an increased pulse current density from -5 to $40 \mathrm{mAcm}^{-2}$ is a substantial benefit.

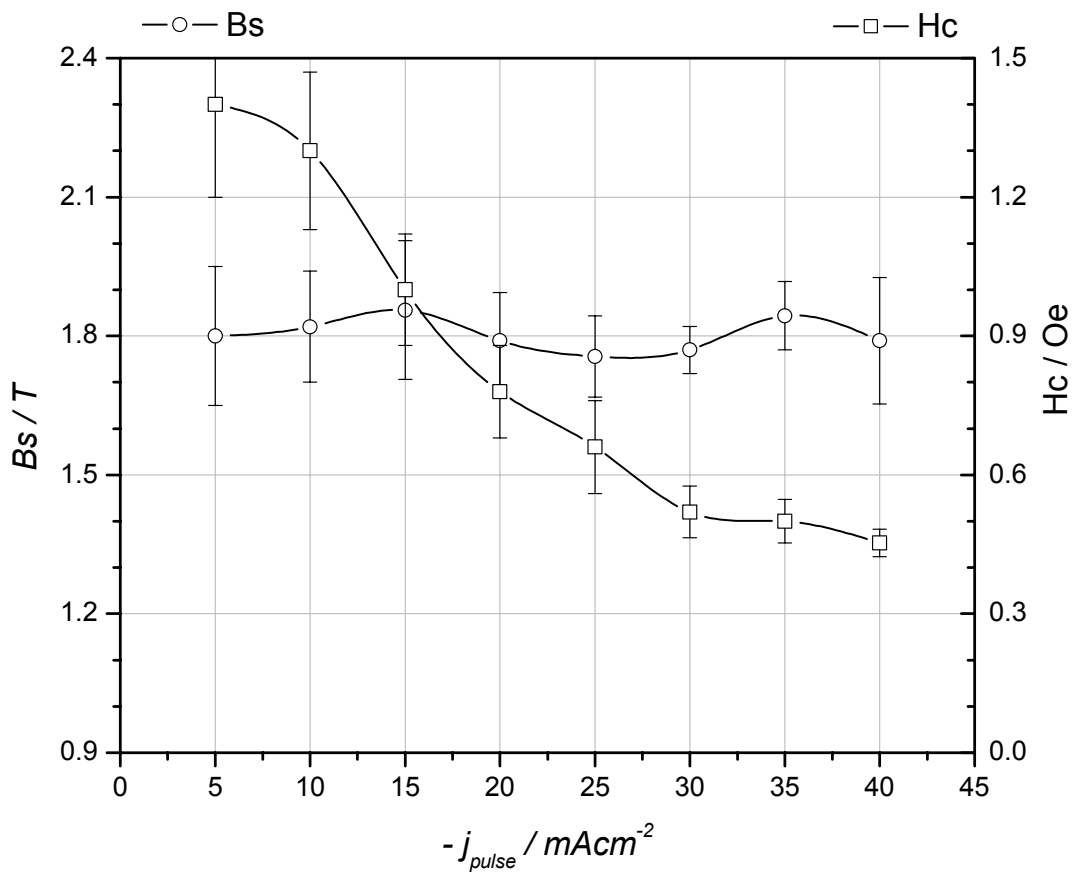

Figure 7. Magnetic properties of the CoFeNi films as a function of pulse current density. Saturation magnetic flux density (Bs - circles) - right axis, coercivity for the easy magnetic axis (Hc,e-squares ) - left axis.

\section{$\underline{\text { 3.5 X-Ray Diffraction Measurements }}$}

The XRD analysis (Figure 8) of the deposited CoFeNi films shows that the films deposited at lower pulse currents are face centered cubic (FCC), while for current densities above $-30 \mathrm{mAcm}^{-2}$, the predominant structure is body centered cubic (BCC). The transition region where the $\mathrm{BCC}$ phase appears but the FCC is still dominant starts with the pulse current of $-20 \mathrm{mAcm}^{-2}$ (shoulder at $2 \theta=45.3^{\circ}$ on $-20 \mathrm{mAcm}^{-2}$ curve in Figure 8) and extends over $-25 \mathrm{mAcm}^{-2}$ and $-30 \mathrm{mAcm}^{-2}$ where no difference in mutual ratio 
between areas of FCC and BCC peak is observed. The dominant BCC phase in the films deposited with pulse currents higher than $-30 \mathrm{mAcm}^{-2}$ is consistent with an increase of $\mathrm{Fe}$ content in the deposit (Figure 6). This can be interpreted as a consequence of anomalous codeposition effect discussed in the previous paragraph, (Figure 6). The crystal structure changing from $\mathrm{FCC}$ to $\mathrm{FCC}+\mathrm{BCC}$ does not seem to induce any measurable change in the magnetic moment of the CoFeNi films ( 1.8 T, Figure 7). Previously reported results for CoFeNi films deposited with the direct current (DC) method indicate that desirable region for soft CoFeNi films is the one where either both crystal phases coexist or the alloy composition is on the boundary of the two-phase region ${ }^{2,3,7,9,33}$. Similarly, our data indicate that in the case of the pulse deposited $\mathrm{CoFeNi}$ films, the magnetic softness is promoted with the appearance of BCC phase (Figure 6 - Figure 8). With more BCC phase taking over the overall deposit structure the coercivity of $\mathrm{CoFeNi}$ films saturates at the level of $\sim 0.5 \pm 0.05$ Oe (Figure 8 ).

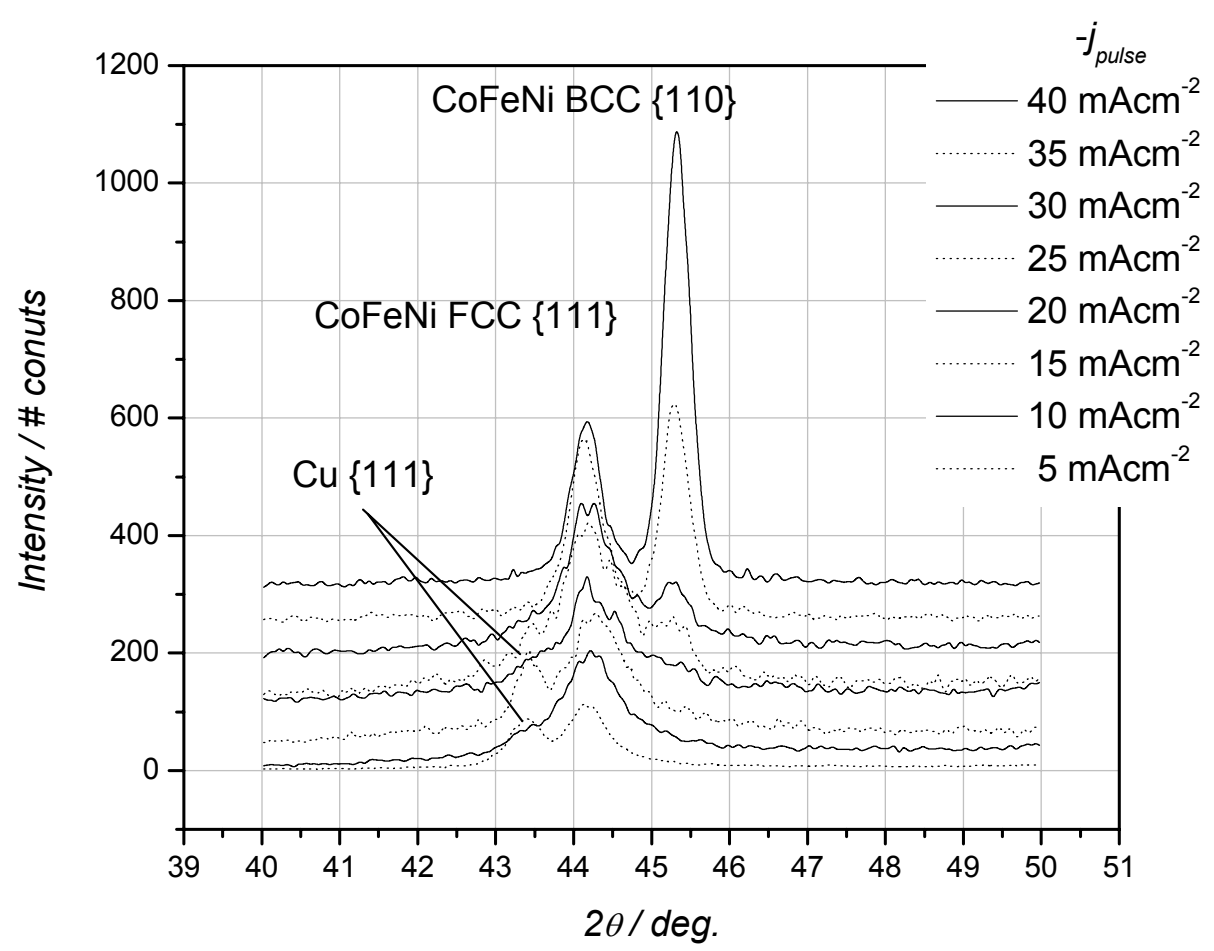

Figure 8. The XRD $2 \theta$ scans for the CoFeNi films deposited with different pulse current densities. Data shown only for FCC $\{111\}\left(2 \theta=44.25^{\circ}\right)$, and $B C C\{110\}\left(2 \theta=45.3^{\circ}\right)$ peaks, the rest of the scan is neglected. The peak visible at $2 \theta=44.3^{\circ}$ on some of the scans is due to $\mathrm{Cu}$ substrate. The spectra are offset for clarity purpose.

Both, BCC + FCC phases, are observed in the deposit for a broad range of pulse currents $\left(-20\right.$ to $-40 \mathrm{mAcm}^{-2}$, Figure 8$)$. In the same range, the measured coercivity change is mild, almost being within the error bar of the measurements ${ }^{34}$, which demonstrates that once the FCC and BCC crystallographic phases coexist together, a very small improvement in coercivity can be achieved by large increase in pulse current density $(\sim 100 \%)$. 


\section{$\underline{\text { 3.6 Secondary Ion Mass Spectroscopy Measurements }}$}

The SIMS analysis investigated C, S and O concentration (w\%) in the CoFeNi films deposited with different pulse current densities. The results are presented in Figure 9a. In Figure 9b these results are re-plotted combining Figure 2 and Figure 9a for the clarity of the future discussion. The results show that the maximum content of $\mathrm{C}$ and $\mathrm{S}$ in $\mathrm{CoFeNi}$ is found for films deposited at a current density of $-20 \mathrm{mAcm}^{-2}$ (Figure $9 \mathrm{a}$ ). For current densities between $-5 \mathrm{mAcm}^{-2}$ to $-20 \mathrm{mAcm}^{-2}$ and immediately higher ones, -20 $\mathrm{mAcm}^{-2}$ to $-30 \mathrm{mAcm}^{-2}$ the $\mathrm{C}$, and $\mathrm{S}$ content in the deposit is decreasing. Eventually for the pulse current densities above $-35 \mathrm{mAcm}^{-2}$ a gradual increases in $\mathrm{S}$, and $\mathrm{C}$ content is observed again (Figure 9a). The oxygen content in the CoFeNi films has two apparent maximums; for current densities of $-20 \mathrm{mAcm}^{-2}$ and $-30 \mathrm{mAcm}^{-2}$.
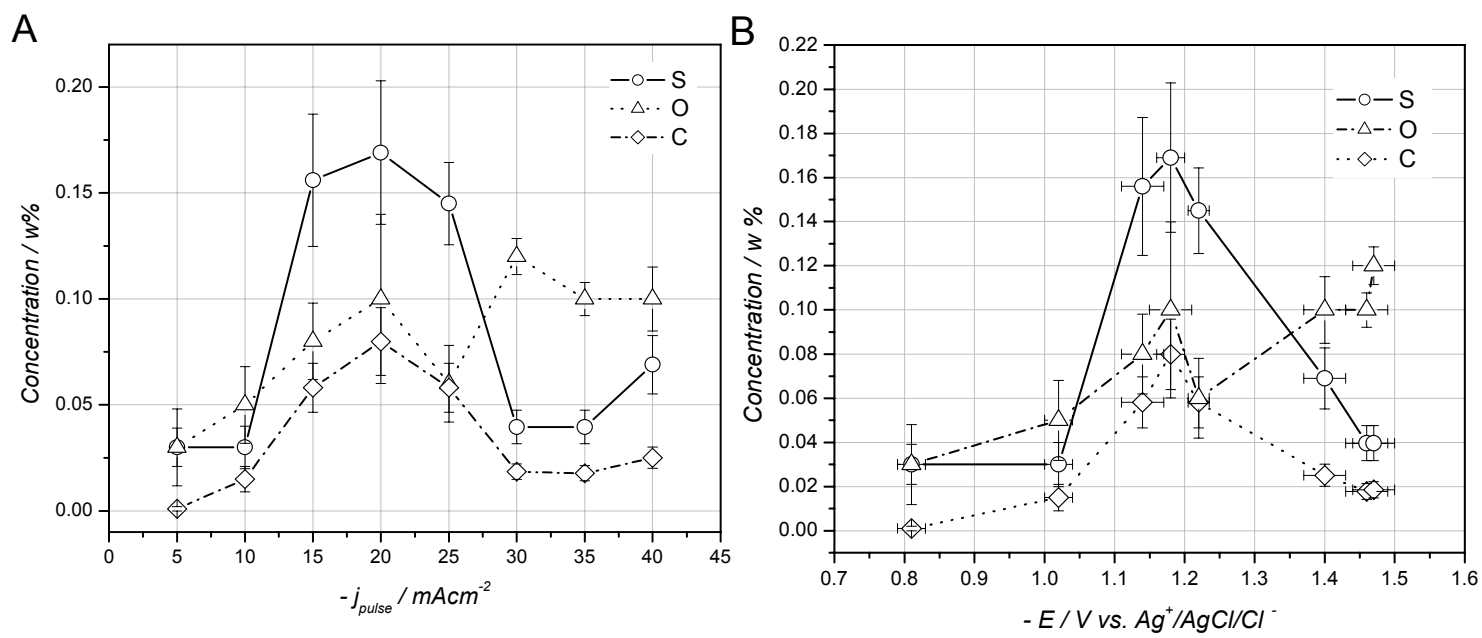

Figure 9. The SIMS analysis of $S, C$, and $O$ inclusion content in the CoFeNi deposit as a function of the pulse current density $(A)$ and the electrode potential during the pulse stage (B).

The SIMS data for $\mathrm{S}, \mathrm{O}$, and $\mathrm{C}$ can be analyzed through the loop of the results presented in the Figure 5. It is obvious that the highest content of $\mathrm{S}$ and $\mathrm{C}$ in the deposit is observed for the pulse currents where the corresponding potential of the CoFeNi surface is in the range where the maximum adsorption and coverage of additives on the CoFeNi surface occurs (Figure $9 \mathrm{~b}$ and Figure 5$)^{35}$. The source of the elementary S, and C in deposit can be directly connected to the molecular structure of Saccharin and SLS ${ }^{6}$. The main source of the $\mathrm{S}$ in the deposit is probably the adsorbed Saccharin on the CoFeNi surface. The incorporation into the deposit is going either through the adsorption-electro reduction mechanism ${ }^{36,37}$ or as a physical incorporation ("burying") of entire molecules during the nucleation and growth of the metal deposit ${ }^{38,39}$. The latter mechanism is attributed also to the incorporation of $\mathrm{O}$ and $\mathrm{C}$ from Saccharin and $\mathrm{O}, \mathrm{C}$, and $\mathrm{S}$ from SLS too. The existence of the burying mechanism of additive incorporation is also evident from the $C$ concentration profile following the $S$ concentration profile (Figure $9 a$ and $9 b$ ). The physical incorporation of entire molecules or certain atomic groups occurs with sulfur and carbon atoms as their integral part explaining the similar dependences for $\mathrm{S}$ and $\mathrm{C}$ curves observed in Figure 9. Both above mentioned mechanisms are dependent on 
surface coverage of additives ${ }^{3,23,36,39}$. Because of that, it is not surprising that the highest concentrations of $\mathrm{S}$ and $\mathrm{C}$ in deposit are observed at potentials where the maximum coverage of additives is expected ${ }^{35}$ (Figure $9 \mathrm{~b}$ and Figure 5). In our case the potential of maximum additive coverage, $\theta_{a p p},(-1.2 \mathrm{~V}$ to $-1.29 \mathrm{~V})$ and maximum additive incorporation $(-1.18 \mathrm{~V})$ are approximately the same ${ }^{40}$. For the pulse currents where the potential of the CoFeNi surface is below $-1.1 \mathrm{~V}$ and above $-1.35 \mathrm{~V}$ the additive coverage is significantly reduced (Figure 5). However, there are still traceable amounts of S and C in the deposit. According to the models in the literature the additive incorporation rate via the burying mechanism is also proportional to the deposition rate (current) ${ }^{38,39}$. An apparent increase of $\mathrm{S}$, and $\mathrm{C}$ content in the deposit observed for the current densities above $35 \mathrm{mAcm}^{-2}$ clearly demonstrate this effect (Figure 9a).

The oxygen content in the CoFeNi deposit can be interpreted through the existence of two separate sources. As we see in Figure $9 a$ and $9 b$, the first maximum is observed at the same potential as for $\mathrm{S}$, and $\mathrm{C}$ (Figure 9). The $\mathrm{O}$ concentration dependence closely follows the one for $\mathrm{C}$ and $\mathrm{S}$. The reason for this is that $\mathrm{O}$ in this potential range (pulse currents) is mainly coming from the additives that were buried in the deposit during the electrodeposition. However, as mentioned before while discussing results in Figure 6, the pulse current densities above $-25 \mathrm{mAcm}^{-2}$ and lower coverage of additives on the electrode surface (Figure 5) are responsible for the formation of insoluble intermediates of the $\mathrm{Fe}_{\mathrm{x}}(\mathrm{OH})_{\mathrm{y}}$ type on the CoFeNi surface. In this situation they become a main source if $\mathrm{O}$ in the deposit. Instead of buried additive molecules, now for higher pulse currents, the buried iron hydroxide becomes a dominant source of $\mathrm{O}$ in the deposit. This mechanism has been already discussed for inclusion of $\mathrm{O}$ in Permalloy ${ }^{41}, \mathrm{CoFeNi}^{6}$ and more recently for $\mathrm{CoFe}$ magnetic films ${ }^{42}$. The largest content of $\mathrm{O}$ in the deposit measured for the pulse current densities of $-30 \mathrm{mAcm}^{-2}$ to $-40 \mathrm{mAcm}^{-2}$ where potential of the CoFeNi surface falls in the range of the lowest additive coverage (Figure 5 and Figure 9), is just confirming this argument.

There is no clear correlation between the concentration of $\mathrm{S}, \mathrm{C}$ and $\mathrm{O}$ in the $\mathrm{CoFeNi}$ deposit and its magnetic properties and crystal structure. The saturation magnetic flux density is more likely dependent mainly on the alloy composition rather than on inclusion content as long as they are present in very small amounts $(<1$ at $\%)$.

Nevertheless, it is interesting that we observe the appearance of the BCC phase in the $\mathrm{CoFeNi}$ alloy deposited with the pulse currents where the incorporation rates for $\mathrm{S}$ and $\mathrm{C}$ inclusions are the largest. In the same pulse current range a significant decrease in coercivity is observed. Further decrease of S, and C content in the deposit has no clear correlation with the $\mathrm{BCC}$ phase gradually taking over the CoFeNi matrix. An increased $\mathrm{O}$ inclusion content can be connected indirectly to the Fe increase in the deposit resulting in gradual domination of the BCC phase in the deposit.

\subsection{Application}

Improved surface finish of the electrodeposit has been for a long time the primary reason for use and formulation of different additives in the electroplating baths. Through the years, the right additives and conditions for electrodeposition were based on the experience and many trial and error experiments. As the electrodeposition becomes a common tool of nano-technology ${ }^{43,44,45}$ it is important to emphasize the importance of understanding the right conditions at the electrochemical interface, which lead to 
formation of desired structures, surfaces and successful electrodeposition at nano-scale. As an example, in Figure 10, a typical shape of electrodeposited CoFeNi writing pole with lateral dimension necessary for future $\mathrm{Tb} / \mathrm{in}^{2}$ recording density is presented. The goal of the electrodeposition process is to produce these structures without any depression in their most critical part- its' center $^{11}$. The pulse deposition method has been already proven successful for this application ${ }^{11}$. The structures in Figure 10 were produced by the same pulse deposition process and bath formulation discussed in the previous text. However, the left image shows a smooth and desirable structure across the pole axes, while the right one is showing a rough deposit surface with an indication of Laplace growth in the region where the field gradient is the largest during the throughmask deposition. The main difference between these structures is the potential of the electrode surface during the pulse stage. The structure presented in the left image is produced by pulse current where the potential of the surface was in the range of maximum additive adsorption. The pulse current where the potential of the electrode surface was such that the additive surface coverage is significantly reduced produced the structures shown on the right image. As clear from Figure 10, the sufficient leveling action during the pulse deposition occurs only if the conditions at the electrochemical interface allow the appropriate interaction of additives with the metal deposit ${ }^{25}$. A good additive formulation having inappropriate conditions on the metal/solution interface will eventually yield a poor pulse deposition results (Figure 10, right image).
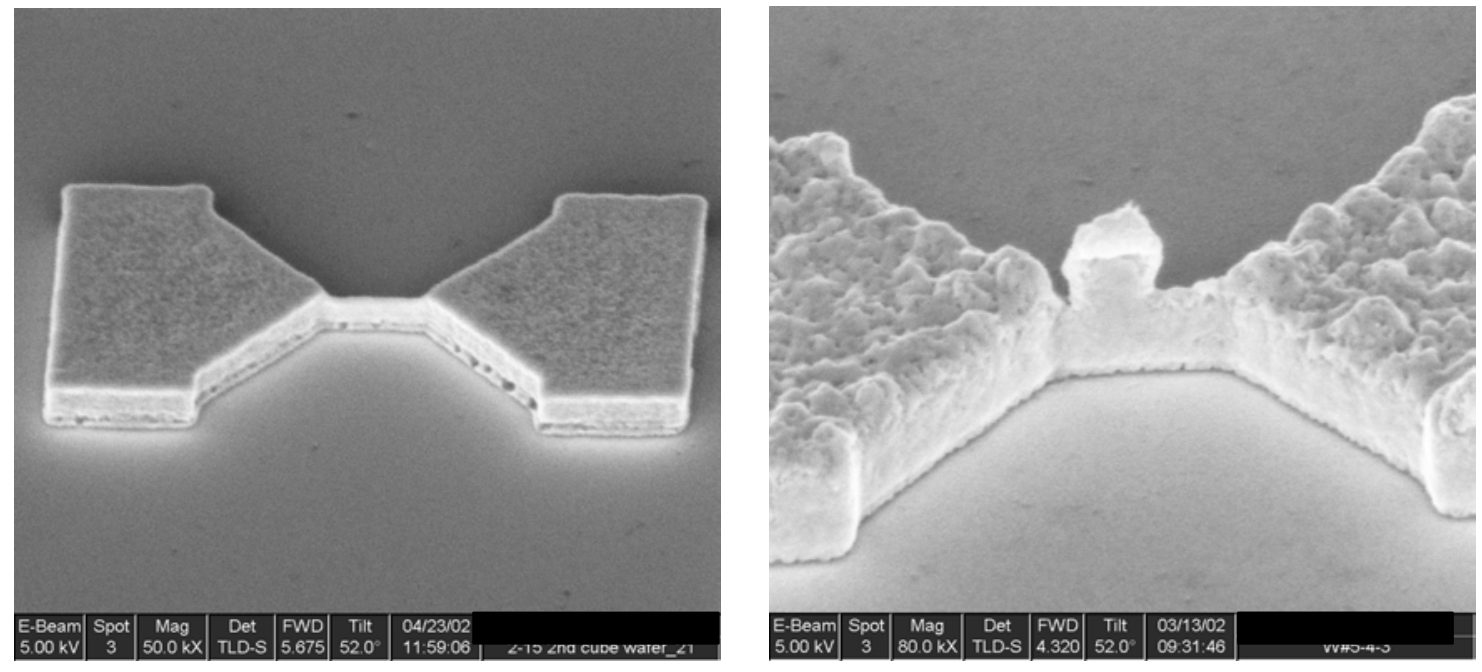

Figure 10. The SEM images of the CoFeNi electrodeposited top pole structures. Magnification on the left image is 50,000x and on the right one is 80,000x. Approximate dimension of the pole tip are: width $-55 \mathrm{~nm}$, length $-600 \mathrm{~nm}$ and height $-550 \mathrm{~nm}$.

\section{CONCLUSION}

The results presented in this paper demonstrate that properties of the pulse deposited CoFeNi magnetic films are very dependent on the pulse current regime and conditions at the electrochemical interface. Additives, Saccharin and SLS, are found to be the main source of incorporated $\mathrm{S}$ and $\mathrm{C}$ in the deposit possibly through the electro reduction $(\mathrm{S})$ and physical incorporation $(\mathrm{S}$, and $\mathrm{C}$ ) mechanisms. The potentials of maximum additive incorporation and maximum additive adsorption were found to be approximately the same for the given experimental conditions. The source of oxygen 
content in the deposit was attributed to both; incorporated additives and iron oxide. The anomalous co-deposition effect was found to be moderate in the potential range where maximum surface coverage of additives (Saccharin) is expected influencing the composition of the CoFeNi films and the crystal structure changes to be relatively mild for a broad range of pulse current densities. The relative potential of the CoFeNi surface during the pulse stage with respect to the potential of maximum additive adsorption, for the same additive formulation and chemistry of the plating bath, was found to be of the crucial importance for the successful deposition of the features at the nano-scale. We believe that these findings will improve our current understanding of the role of additives in pulse electrodeposition of magnetic alloys on nanoscale with desired structural and magnetic properties.

\section{ACKNOWLEDGMENT}

Authors would like to acknowledge Prof. N. Dimitrov for useful discussions regarding the subject.

\section{REFERENCES}

${ }^{1}$ M. Izaki in: Modern Electroplating, $4^{\text {th }}$ ed, M. Schlesinger and M. Paunovic, Editors, p. 468, John Willey \& Sons, New York (2000).

2 T. Osaka, M. Takai, K. Hayashi, K. Ohashi, M. Saito, and K. Yamada, Nature, 392, 796 (1998).

${ }^{3}$ T. Osaka, T. Sawaguchi, F. Mizutani, T. Yokoshima, M. Takai, and Y. Okinaka, J. Electrochem. Soc., 146, 3295 (1999).

${ }^{4}$ B. N. Popov, K-M. Yin, and R. E. White, J. Electrochem. Soc., 140, 1321 (1993).

${ }^{5}$ T. Osaka, M. Takai, T. Y. Sogawa, T. Momma, K. Ohashi, M. Saito and K. Yamada J. Electrochem. Soc.,146, 2092 (1999).

${ }^{6}$ I. Tabakovic, S. Remer, V. Inturi, P. Jalen, and A. Thayer, J. Electrochem. Soc., 147, 219 (2000).

${ }^{7}$ I. Tabakovic, V. Inturi, and S. Riemer, J. Electrochem. Soc., 149, C18 (2002).

${ }^{8}$ X. Liu, G. Zangari, and L. Shen, J. Applied Phys., 87, 5410 (2000).

${ }^{9}$ X. Liu, G. Zangari, M. Shamsuzzoha, J. Electrochem. Soc., 150, C159 (2003).

${ }^{10}$ Foreign elements (inclusions) are considered the ones that are not metal in origin.

${ }^{11}$ S.R. Brankovic, K. Sendur, T.J. Klemmer, X. M. Yang and E.C. Johns, in Magnetic Materials Processes and Devices VII and Electrodeposition of Alloys, S. Krongelb, L. T. Romankiw, J.-W. Chang, Y. Kitamoto, J. W. Judy, C. Bonhôte, G. Zangari and W. Schwarzacher, PV 2002-27, p. 269, The Electrochemical Society Proceedings Series, Pennington, NJ (2002).

12 The thickness of the samples was verified by 61 step measurements and by integration of the charge during deposition and dissolution of CoFeNi films.

${ }^{13}$ J. V. Powers and L. T. Romankiw, US Patent \# 3652442 (1972).

${ }^{14} \mathrm{CoFeNi}$ films were deposited using pulse current of $20 \mathrm{mAcm}^{-2}$ with $10 \%$ duty cycle. The other deposition parameters and bath chemistry are defined in Ref. (7) and Ref. (11). ${ }^{15} \mathrm{http}: / / w w w . c e a . c o m / e v a n s e a s t / e v a n s e a s t . h t m$

${ }^{16}$ D. A. Johns Principles and Prevention of Corrosion, $2^{\text {nd }}$ edition, p. 110, Prentice Hall Inc, NJ (1996). 
${ }^{17}$ I. D. Raistrick in: Impedance Spectroscopy, J.R. Macdonald Editor, p. 75, J. Wiley \& Sons, NY (1987).

${ }^{18}$ M. E. Orazem, P. Agarwal, and L.H. Garcia-Rubio, Material Science Forum 195, 563 (1995)

${ }^{19}$ B.B. Damaskin, O.A.Petri, and V. V. Batratkov, Adsorption of Organic Compounds on Electrodes, p. 259, Plenum Press NY (1971).

${ }^{20}$ J. O’M. Bockris and A. K. N. Reddy Modern Electrochemistry II, p. 791, Plenum Press NY (1970).

${ }^{21}$ J.O'M. Bockris and D.A. J. Swinkels, J. Electrochem. Soc. 111, 736 (1964).

${ }^{22}$ C. Buess-Herman, Progress in Surface Science, 46, 335 (1994). See also Ref (19) p. 269.

${ }^{23}$ V. Ivanova, and C. Buess-Herman, J. Electroanal. Chem. 552, 45 (2003).

${ }^{24}$ For some applications, a minimized content of additives in the plating bath is required. Formation of condensed film on the CoFeNi surface means that additive action during deposition will be independent on their concentration in the bulk solution unless the transport limited conditions for additive arrival on the surface are established.

${ }^{25}$ J.O'M. Bockris and U.M. Khan, Surface Electrochemistry, p. 375, Plenum Pub. Corp. NY (1993).

${ }^{26}$ A. R. Despic in: Comprehensive Treatise of Electrochemistry, B. E. Conway, J. O'M. Bockris, E. Yeager, S. U. M. Khan, R. E. White, Editors, vol. 7, p. 451, Plenum Press, NY (1983).

${ }^{27}$ Corrosion Handbook, ed. H. H. Uhlig, p.1144, J. Willey \& Sons, NY (1948).

${ }^{28}$ In our case, a typical current efficiency during pulse deposition of CoFeNi alloys is $70 \pm 3 \%$. The efficiency for pulse deposition currents where the potential of the electrode surface falls in the range of maximum additive adsorption is increased to $\sim 85 \%$.

${ }^{29}$ A. Brenner, Electrodeposition of Alloys, vol. 1, Academic Press, NY (1963).

${ }^{30}$ J.O'M. Bockris, D. Drazic, and A.. R. Despic, Electrochimica Acta, 4, 325 (1961).

${ }^{31}$ F.E. Rasmussen, J. T. Ravinkilde, P.T. Tang, O. Hansen, and S. Bouwstra, Sensors and Actuators, 92, 242 (2001).

${ }^{32}$ Ferromagnetism, R.M. Bozorth Editor, p. 264, IEEE Press, NY (1978).

${ }^{33}$ T. Osaka, M. Takai, K. Hayashi, and Y. Sogawa, IEEE Transaction on Magnetic, 34, 1432 (1998).

${ }^{34}$ In this range of the potential, considering the error bar of the measurement, the coercivity can be considered as constant.

${ }^{35}$ The apparent additive coverage $\theta_{a p p}(\%)$ can be approximated by $\theta=\frac{C_{0}-C}{C_{0}-C_{m}}$, where $C$, $C_{m}$ and $C_{0}$ are the capacity of the double layer at additive surface coverage $\theta$, capacity of double layer at $\theta=\theta_{\max }$ and capacity of double layer at $\theta=0$ (no additives in the solution). The data in Figure 5 (diamonds) showing the apparent additive coverage are recalculated using the results for $C_{d l}$ in solution containing $0.5 \mathrm{~g} / \mathrm{L}$ of additives and results for $C_{d l}$ measured in background solution (no additives, data not shown here). The dependence is shown for the illustration (qualitative) purpose.

${ }^{36}$ J. Edwards, Trans. Inst. Metal Finish, 39, 52 (1962).

${ }^{37}$ J. Edwards, Trans. Inst. Metal Finish, 41, 140 (1964).

${ }^{38}$ K.-M. Yin, J. Electrochem. Soc. 150, C435 (2003)

${ }^{39}$ K.-M. Yin, J. Electrochem. Soc. 145, 3851 (1998)

${ }^{40}$ Having on mind that the maximum additive incorporation potential is determined from the data in Figure 9b, which are derived from Figure 9a and Figure 2 where the increment 
of the pulse current density is $5 \mathrm{mAcm}^{-2}$, it is likely to consider determination of potential of maximum additive incorporation with an accuracy $\pm 0.03 \mathrm{~V}$.

${ }^{41}$ S. Gadad, and T. M. Harris, J. Electrochemical Soc. 145, 3699 (1998).

${ }^{42}$ T. Osaka, T. Yokoshima, D. Shinga, K. Imai, and K. Takashima., Electrochem. Solid State Lett., 6, C53 (2003).

${ }^{43}$ M. Data, and D. Landolt, Electrochemica Acta, 45, 2535 (2000)

${ }^{44}$ H. Honoma, Electrochemica Acata, 47, 75 (2001)

${ }^{45}$ J. W. Schultze, and A. Bressel, Electrochimica Acta, 47, 3 (2001). 